INTERNACIONAL

\title{
Lineamientos para la vinculación entre cambio climático y derechos humanos en los Estados del Sistema Interamericano a la luz de la Opinión Consultiva 23/17
}

\author{
Guidelines for the link between Climate Change and Human Rights in the States \\ of the Inter-American System in the light of the Advisory Opinion 23/17
}

\author{
Andrea Lucas Garín (iD \\ Universidad Autónoma de Chile \\ Tiare García Garcés iD \\ Universidad Finis Terrae, Chile
}

\begin{abstract}
RESUMEN Producto de los grandes desafíos del último y del presente siglo por preservar la sustentabilidad y con antecedentes científicos en progreso, se ha logrado demostrar que el cambio climático está interfiriendo en los derechos humanos, por lo que enfrentarlo se vuelve impostergable. Si bien esta interrelación es evidente, la Corte Interamericana de Derechos Humanos por primera vez se ha ocupado de manera expresa y sistemática de la relación innegable entre la protección del medio ambiente y el cumplimiento de los derechos humanos. Este breve trabajo versará sobre la Opinión Consultiva «Medio ambiente y derechos humanos», analizándola en torno a los lineamientos para las políticas que de ella se desprenden, en directa alineación con el Acuerdo de París sobre el Cambio Climático, que obliga a los Estados de nuestra región que lo han ratificado a la toma de medidas para enfrentar este fenómeno.
\end{abstract}

PALABRAS CLAVE Cambio climático, derechos humanos, Opinión Consultiva, políticas domésticas.

ABSTRACT Product of the great challenges of the last and the present century to preserve the sustainability and with scientific antecedents in progress, it has been demonstrated that the climate change is interfering in the Human Rights for what to face it becomes unpostponable. While this interrelation is evident, the Inter-American Court of Human Rights for the first time has expressly and systematically addressed the un- 
deniable relationship between the protection of the environment and the realization of human rights. This short work will deal with the Advisory Opinion "Environment and Human Rights", analyzing it around the guidelines for the policies derived from it, in direct orientation with the new Paris Agreement on Climate Change that binds the States of our region that have ratified it to take measures to face this phenomenon.

KEYWORDS Climate change, human rights, Advisory Opinion, domestic policies.

\section{Introducción}

Las consecuencias palpables que el cambio climático está teniendo en nuestra sociedad y cómo éstas son afrontadas representa lo que en políticas públicas se denomina wicked problem ("problema retorcido», malvado o perverso), siguiendo el célebre trabajo de Rittel y Webber (1973: 161). Es decir, podemos ratificar que el cambio climático es un problema retorcido. La complejidad del abordaje que requiere el cambio climático hace imposible encontrar una única perspectiva para asumirlo.

De este modo, la perspectiva de derechos humanos suma visiones relevantes para afrontar el cambio climático, sin ser la única posible. En ese contexto, este trabajo comentará la auspiciosa Opinión Consultiva OC-23/17, sobre «Medio ambiente y derechos humanos», de la Corte Interamericana Derechos Humanos, dictada el 15 de noviembre de 2017 y notificada el 7 de febrero de $2018 .{ }^{1}$

El trabajo se concentrará en los lineamientos para las políticas climáticas que de ella se desprenden, en directa alineación con el Acuerdo de París sobre el Cambio Climático, que obliga a los Estados de nuestra región que lo han ratificado a la toma de medidas para enfrentar este fenómeno. Nuestra reflexión pretende comentar brevemente la Opinión Consultiva y cómo se incorpora en las medidas y acciones que los Estados deben ir emprendiendo de modo de incluir la vinculación del cambio climático con los derechos humanos.

Si bien la Opinión Consultiva aborda dos ejes de obligaciones estatales, una enfrascada en las obligaciones frente a daños transfronterizos, y otra, en las obligaciones estatales frente a posibles daños al medio ambiente - a efectos de respetar y garantizar los derechos a la vida y a la integridad personal en el marco de la Convención Americana de Derechos Humanos- ${ }^{2}$ es en esta última categoría que se afin-

1. En esta oportunidad no trataremos el valor de las opiniones consultivas para los Estados ni la relación con el control de convencionalidad.

2. Se atiende a este alcance preciso porque así lo fija la Corte en el párrafo 243: «Las obligaciones anteriormente descritas fueron desarrolladas en relación con los deberes generales de respetar y garantizar los derechos a la vida e integridad personal, al ser estos los derechos a los cuales hizo referencia el Estado en su solicitud (supra párrs. 37, 38, 46 y 69). No obstante, lo anterior no significa que estas obligaciones no existan con respecto de los demás derechos que esta Opinión previamente mencionó como particu- 
cará nuestro trabajo frente al especial momento que atraviesa el régimen de cambio climático.

\section{Aproximación general al cambio climático}

Es evidente que la lucha contra el cambio climático es uno de los grandes desafíos del último y presente siglo y, por lo tanto, una tarea impostergable para la sobrevivencia de las futuras generaciones. De esta forma, es indiscutible que sus impactos ya visibles son cada día más acelerados, por lo que no es posible negar que las consecuencias y riesgos son múltiples, generados por el aumento de la temperatura fruto del aumento de los gases de efecto invernadero (GEI) en la atmósfera. Los principales impactos son «el deshielo de zonas polares, aumento del nivel del mar, intensificación de huracanes, ciclones y sequías, alteración del ciclo hidrológico, extinción de especies y proliferación de enfermedades» (Godínez y Viveros, 2016: 11), entre otros.

El Grupo Intergubernamental de Expertos sobre el Cambio Climático (IPCC, por sus siglas en inglés) ${ }^{3}$ confirma tales circunstancias, evidenciando en su último informe de fines del 2014 que el cambio climático es verídico y su mayor fuente es la actividad e influencia humana. ${ }^{4}$

El cambio climático interfiere con el disfrute de los derechos humanos protegidos por el derecho internacional de los derechos humanos, y esto se incrementará con el tiempo a menos que las políticas climáticas cambien dramáticamente, en palabras de Knox (2016: 215).

El sistema internacional de protección del cambio climático está conformado, entre otros instrumentos, por la Convención Marco de Naciones Unidas sobre el Cambio Climático (CMNUCC), vigente desde el año 1994, seguida por el Protocolo de Kioto, vigente hasta el 2020, y un último instrumento multilateral derivado, que es el reciente Acuerdo de París, ${ }^{5}$ que vio la luz en diciembre de 2015, luego de décadas de negociaciones.

El Acuerdo de París incorpora a los derechos humanos de manera expresa en el preámbulo cuando afirma:

larmente vulnerables a la degradación del medio ambiente (supra párrs. 56 a 69)». El destacado es nuestro, porque nos parece relevante recordar esta puerta a otros alcances que la Corte está vislumbrando.

3. Desde su creación en 1988, el IPCC ha elaborado cinco informes, y se encuentra en este ciclo desarrollando el sexto informe de evaluación, el cual estará finalizado en el año 2022 con el reporte de síntesis, según lo acordado en la $43{ }^{\text {a }}$ reunión del IPCC.

4. «Quinto informe de evaluación del Grupo Intergubernamental de Expertos sobre Cambio Climático» (texto original en inglés), IPCC, disponible en https://bit.ly/34DtewG. Téngase en cuenta que, en 2019, el IPCC emitió un reporte especial sobre los impactos del calentamiento global en $1,5^{\circ} \mathrm{C}$. El sexto reporte será publicado en 2022.

5. Para más reflexiones sobre el Acuerdo de París, véase Lucas Garín (2017: 137-167). 
Reconociendo que el cambio climático es un problema de toda la humanidad y que, al adoptar medidas para hacerle frente, las partes deberían respetar, promover $y$ tener en cuenta sus respectivas obligaciones relativas a los derechos humanos, el derecho a la salud (el destacado es nuestro).

En una primera lectura, los Estados deben atender al cambio climático, pero teniendo en cuenta sus respectivas obligaciones relativas a los derechos humanos. Según Bodansky (2016: 313), «La disposición no amplía las obligaciones de los países en materia de derechos humanos; más bien, se refiere a las obligaciones "respectivas" de las partes. Queda por ver si esta referencia pasajera a los derechos humanos proporciona una base sobre la cual construir». Cabe señalar que la esperanza de las organizaciones no gubernamentales que han participado de las negociaciones climáticas era incluir en el Acuerdo una norma expresa sobre derechos humanos en la parte operativa, lo que no se alcanzó en esta oportunidad. ${ }^{6}$

La Opinión Consultiva OC-23/17, sobre «Medio ambiente y derechos humanos», se presenta en el marco del Acuerdo de París de Cambio Climático vigente desde noviembre de 2016. Este Acuerdo ha sido ratificado por un número importante de Estados de nuestro continente americano, y corrobora que el cambio climático es una problemática global que obliga a los Estados a la toma de medidas para enfrentar el fenómeno climático a nivel doméstico, en especial para limitar el aumento de la temperatura global a los $1,5^{\circ} \mathrm{C}$, y en cualquier caso siempre por debajo de los $2{ }^{\circ} \mathrm{C}$.

Este Acuerdo tiene por delante un gran desafío de implementación, que para Viñuales resultará más sofisticado y técnico, e indica además que, al ser menos formal que su antecesor Protocolo de Kioto, es más realista y, por ende, tiene más chances de funcionar. Frente al desafío de la implementación, el autor confirma que el Acuerdo incorpora una conceptualización de la cooperación más integrativa, con visiones más holísticas del cambio climático a nivel global (Viñuales, 2017: 43-45). Agregamos que una visión más holística debe encargarse de interrelacionar el cambio climático con otros temas, como derechos humanos. ${ }^{7}$

6. Para ejemplificar remitimos a la ONG FIMA: Ezio Costa Cordella, «COP 21: Los derechos humanos en las discusiones sobre cambio climático», El Mostrador, 10 de diciembre de 2015, disponible en https:// bit.ly/3r2FNLK.

7. El propio Acuerdo de París propone una visión holística en el artículo 6 para los Estados, en particular en sus contribuciones determinadas a nivel nacional (NDC, por sus siglas en inglés): «8. Las partes reconocen la importancia de disponer de enfoques no relacionados con el mercado que sean integrados, holísticos y equilibrados y que les ayuden a implementar sus contribuciones determinadas a nivel nacional». Atender a cada una de las partes que forman el todo de manera global e integrada de los muchos elementos que los Estados deben considerar para enfrentar el cambio climático (y que publican en sus NDC cada cinco años), es lo que propone el Acuerdo de París para los Estados, y parte de nuestra reflexión en torno a la atención de derechos humanos y cambio climático. 


\section{Enmarcando la Opinión Consultiva en el Sistema Interamericano}

La Opinión Consultiva OC-23/17 nace de una solicitud de Colombia a la Corte Interamericana de Derechos Humanos el 14 de marzo de 2016, en relación con los derechos de las poblaciones isleñas colombianas amenazadas por megaproyectos promovidos por otros Estados, que pueden causar impacto transfronterizo en el ámbito marino. La solicitud es parte de la estrategia de litigación que Colombia ha seguido ante el fallo pronunciado por la Corte Internacional de Justicia en noviembre de 2012, caratulado Nicaragua con Colombia, ${ }^{8}$ que generó la salida de Colombia del Pacto de Bogotá el 28 de noviembre de 2012 y la presentación por parte de Nicaragua en el año 2013, de una nueva demanda ante la Corte Internacional. ${ }^{9}$

Ha sido la primera ocasión en que la Corte Interamericana ha abordado directa, sistemática y expresamente el contenido del derecho humano al medio ambiente sano y sus alcances en el Sistema Interamericano con tanta vehemencia. Asimismo, la Corte exteriorizó las obligaciones derivadas de respetar y garantizar los derechos a la vida e integridad personal en el contexto de la protección al medio ambiente, y cuáles son las obligaciones estatales que se derivan de este derecho humano al medio ambiente sano. Y, algo muy relevante, aborda el alcance extraterritorial de las obligaciones estatales y cómo generan responsabilidad estatal. ${ }^{10}$

Podemos decir que esta Opinión Consultiva se suma a un contexto propicio para las cuestiones ambientales en nuestro continente; pensamos en el Acuerdo Regional sobre Acceso a la Información, Participación Pública y el Acceso a la Justicia en Asuntos Ambientales en América Latina y el Caribe, también conocido como el Acuerdo de Escazú, abierto a la firma de los Estados. ${ }^{11}$ En esta Opinión Consultiva, la

8. Sentencia pronunciada por la Corte Internacional de Justicia en noviembre de 2012 sobre el conflicto entre los Estados de Nicaragua y Colombia, mediante la cual se procedió a resolver la cuestión de fondo del caso sobre la disputa territorial y de delimitación marítima entre ambas repúblicas. Disponible en https://bit.ly/2WozGDa.

9. Para solicitar que en primer lugar se le reconozcan derechos sobre la plataforma continental desde su costa y, en segundo lugar, para solicitar que Colombia cumpla con la sentencia del año 2012. Aunque Colombia estableció que la Corte no tiene competencias en esta nueva demanda, la Corte en 2016 se declaró competente. Actualmente la disputa sigue pendiente, los últimos antecedentes que se mantienen es el cumplimiento de las presentaciones de respuestas ante la Corte, tanto de Nicaragua y Colombia, el 9 de julio de 2018 y 11 de febrero del presente año respectivamente, y ajustado a los plazos otorgados expresamente por la CIJ en el comunicado de prensa 2017/38, 15 de diciembre de 2017, disponible en https://bit.ly/3nvOZpW.

10. Sobre este punto, que no abordaremos en este comentario por razones de espacio, recomendamos a Schönsteiner (2018: 244-248).

11. Sobre la situación de Chile frente al Acuerdo de Escazú, véase Consuelo Contreras, «El Acuerdo de Escazú», La Tercera, 3 de octubre de 2018, disponible en https://bit.ly/3nshNiR. 
Corte Interamericana saluda esta iniciativa como una medida positiva para garantizar el derecho de acceso a la información en esta materia (párrafo 219). ${ }^{12}$

Examinar qué ha definido la Corte Interamericana sobre medio ambiente es importante, porque tendrá consecuencias en esta nueva época del régimen cambio climático que pasará por la implementación del Acuerdo de París. Pensamos que tendrá también consecuencias en el escenario que los Estados americanos están generando para la lucha frente al cambio climático.

\section{Destacados de la Opinión Consultiva}

Son muchos los puntos abordados por la Opinión, por lo que vamos a destacar los que nos parecen más pertinentes en vistas al abordaje del cambio climático. De partida, la Corte reconoce la interrelación entre derechos humanos y medio ambiente, tachándola de innegable. Además, considera que hay una relación en los tres ejes derechos humanos, medio ambiente y desarrollo sostenible. Para la Corte, la consecuencia de esta vinculación es que los derechos humanos afectados por la degradación del medio ambiente incluyen el derecho al medio ambiente sano.

Éste es un auspicioso punto de partida para la Opinión Consultiva, que asume la pregunta sobre qué ocurría con el derecho humano al medio ambiente sano que ha sido recogido por pocos instrumentos del derecho internacional de los derechos humanos de modo directo, ${ }^{13}$ pero sí por la mayoría de las constituciones, en especial en las de nuestro continente, de la mano del constitucionalismo ambiental latinoamericano. ${ }^{14}$

La Corte se ocupa de probar que en el Sistema Interamericano de Derechos Humanos, el derecho humano al medio ambiente sano está consagrado en dos textos vigentes: por un lado y de modo expreso, en el artículo 11 del Protocolo de San Salvador; ${ }^{15}$

12. El 4 de marzo de 2018, América Latina y el Caribe adoptaron en Escazú (Costa Rica), este Acuerdo Regional sobre el Acceso a la Información, la Participación Pública y el Acceso a la Justicia en Asuntos Ambientales, disponible en https://bit.ly/34AU8FM.

13. Siguiendo a Boyle, el artículo 24 de la Carta Africana sobre los Derechos Humanos y de los Pueblos (Carta de Banjul) indica: «Todos los pueblos tendrán derecho a un entorno general satisfactorio favorable a su desarrollo». Es el texto del derecho internacional de los derechos humanos que mejor integra los derechos humanos con el medio ambiente. Boyle expresa: «Ningún otro tratado contiene nada directamente comparable. Además, los derechos creados por la Convención Africana son derechos de los pueblos, no derechos individuales» (Boyle, 2011: 10; la traducción es nuestra). En este marco, lo que argumenta la Corte Interamericana basándose en el derecho positivo tiene mucho valor.

14. Nos referimos al concepto acuñado por Brañes (2001: 45 y ss.).

15. El Protocolo Adicional a la Convención Americana sobre Derechos Humanos en materia de Derechos Económicos, Sociales y Culturales (Protocolo de San Salvador) dispone en el artículo 11, derecho a un medio ambiente sano: «1. Toda persona tiene derecho a vivir en un medio ambiente sano y a contar con servicios públicos básicos; 2. Los Estados parte promoverán la protección, preservación y mejoramiento del medio ambiente». 
por otro lado, por el artículo 26 de la Convención Americana, dedicado a los derechos económicos, sociales y culturales (DESC).

En general, el derecho a un medio ambiente sano se ubica dentro de los DESC o, simplemente, derechos sociales. En el marco del Sistema Interamericano de Derechos Humanos, el artículo 26 del Pacto de San José se erige como única norma referente a los DESC, $\mathrm{y}$ "pareciera que el peso de la corriente constitucional que considera a los derechos económicos, sociales y culturales como "derechos programáticos", ha pesado demasiado como para abrir las puertas de su acceso, exigibilidad y justiciabilidad de manera contundente», indica Gonzalo Aguilar (2017: 160).

No trataremos de modo profundo en este trabajo el camino que los DESC han tenido en el sistema regional. Debe señalarse que la Corte Interamericana ha ido abriendo camino para el reconocimiento de los DESC, lo que se materializa en el caso Lagos del Campo con Perú, del 31 de agosto de 2017. De manera destacada, se suma esta Opinión Consultiva en ese camino de consolidación de los DESC en nuestro contexto regional. ${ }^{16}$

En relación con el contenido del derecho humano al medio ambiente sano, la Corte considera que es un derecho con connotaciones tanto individuales como colectivas. La dimensión colectiva se revela al mostrarse el interés universal que también lo es de las generaciones presentes y futuras. La dimensión individual se refiere a que la vulneración del derecho puede tener tanto repercusiones directas como indirectas (párrafo 59 y ss.).

De este modo, también la Corte Interamericana asume que el derecho humano al medio ambiente sano se conecta con otros derechos, como a la salud, a la integridad personal, a la vida, etc. La autonomía del derecho humano al medio ambiente sano queda demostrada con la existencia en los dos textos legales del Sistema Interamericano; pero, además, la conectividad indirecta asegura de todos modos su existencia (párrafo 54, 62 y ss.).

Para finalizar estos destacados, la Opinión aborda la distinción entre dos grupos en los que se clasifican los derechos vinculados al medio ambiente: en primer lugar, los derechos cuyo disfrute es vulnerable a la degradación al medio ambiente -es decir, aquí el énfasis es la perspectiva de derechos sustantivos-; la segunda clasificación es que los derechos se relacionan con la mejor formulación de políticas ambientales, en que el enfoque es de derechos procedimentales. ${ }^{17}$

16. Para profundizar sobre el camino de los DESC, recomendamos Ferrer Mac-Gregor (2017: 1-258).

17. «El enfoque basado en los derechos humanos constituye un marco conceptual fundado en las normas internacionales de derechos humanos y orientado a su promoción y protección. [...] Por lo tanto, este enfoque integra de manera congruente y sistemática los principales principios y estándares de derechos humanos en los planes, políticas y programas; se centra en los derechos, no en las necesidades; presta atención a los procesos y los resultados; y focaliza la atención en los grupos más vulnerables» 


\section{Las derivaciones de la Opinión Consultiva para las políticas climáticas en los Estados americanos}

La Opinión Consultiva contiene una mención expresa del cambio climático y lo utiliza para ejemplificar las afectaciones de los derechos humanos que pueden derivarse del calentamiento global. Así se sostiene en el párrafo 47: «Esta Corte ha reconocido la existencia de una relación innegable entre la protección del medio ambiente y la realización de otros derechos humanos, en tanto la degradación ambiental y los efectos adversos del cambio climático afectan el goce efectivo de los derechos humanos» (el destacado es nuestro). Resulta llamativo en la Opinión Consultiva las muchas menciones al cambio climático, en especial en los ejemplos que brinda de los argumentos que va sosteniendo. ${ }^{18}$

Consideramos que este esfuerzo de enlazar el medio ambiente con el cumplimiento de los derechos humanos es parte del ejercicio regular con el cual Corte procura ir dibujando los alcances de los derechos consagradas en la Convención, de modo también de ir actualizándolos. Asimismo, si pensamos hoy en medio ambiente, resulta imposible no conectarlo con cambio climático; no sólo porque desde la perspectiva de los sistemas nacionales, el cambio climático es un área de políticas públicas muy activa ${ }^{19}$ sino porque además es un área en la cual los ciudadanos están dispuestos a litigar contra sus gobiernos para exigir acciones climáticas. ${ }^{20}$

La Corte expone que las obligaciones de los Estados para proteger y concretar el derecho a la vida y a la integridad personal, en relación con daños al medio ambiente, ${ }^{21}$ son:

- Obligación de prevenir daños ambientales significativos.

- Deber de regular, supervisar y fiscalizar el daño ambiental.

- Deber de aplicar el principio de precaución.

- Obligación de cooperar de buena fe para la protección del daño ambiental.

- Deber de notificar a otro Estado potencialmente afectado por daño ambiental de una actividad realizada bajo su jurisdicción.

(Cepal y ACNUDH, 2016: 19). De este modo, el enfoque de Derechos Humanos requiere integrarse de manera efectiva en las políticas ambientales.

18. Se registran 41 menciones al cambio climático a lo largo de la Opinión Consultiva.

19. Para confirmar esta afirmación, remitimos a Lucas Garín (2018: 587-625).

20. Recomendamos a Peel y Osofsky (2015: 9), quienes se ocupan de demostrar en su obra la relevancia de la litigación en los tribunales y cómo esto es parte de la gobernanza climática, con consecuencias reales para el logro de medidas de mitigación y adaptación climáticas.

21. Remitimos al punto 3 del resumen oficial emitido por la Corte Interamericana, disponible en https://bit.ly/3ahsPE3. 
- Deber de garantizar el acceso a la información ambiental.

- Deber de garantizar la participación pública de las personas bajo su jurisdicción.

- Debe de garantizar el acceso a la justicia.

A continuación, analizaremos estas obligaciones en clave climática, de modo de tener pistas sobre la aplicabilidad que debieran tener los Estados americanos de estas obligaciones cuando deban tomar medidas para proteger a sus poblaciones del cambio climático. ${ }^{22}$

Sobre la obligación de prevenir daños ambientales significativos, más el deber de regular, supervisar y fiscalizar el daño ambiental

Desde la perspectiva de los Estados, ellos deben velar por que su territorio no sea utilizado de modo de causar daño significativo a otro Estados o zonas fuera de su límite; por ende, tienen la obligación de evitar causar daños transfronterizos y de adoptar medidas para que las actividades desarrolladas en su territorio no causen daño a otro Estado.

La Corte toma las obligaciones de los Estados en materia ambiental de un modo clásico en lo que respecta a un Estado frente a otro Estado. Podríamos decir que este ámbito está fuera del alcance de la Corte Interamericana, que es un órgano judicial encargado de resolver problemas entre Estados e individuos.

Pero la Corte no sólo aborda estas obligaciones, sino que también se introduce en las obligaciones de los Estados frente a su propia población. Ahí llegamos al deber de adoptar medidas para que las actividades desarrolladas en su territorio no produzcan daño a otro Estado ni a los individuos sujetos a su jurisdicción.

El deber se relaciona con el principio de prevención, que se refiere estrictamente a la necesidad de que los Estados tengan políticas ambientales, con institucionalidad ambiental, y tribunales que se hagan cargo del proceso sancionatorio, para que el tema ambiental y en este caso el cambio climático sea parte de la agenda pública.

Esta efectivización del principio de prevención ya está consagrado a nivel internacional desde la Declaración de Estocolmo de 1972 (el célebre Principio 21), y repetido en la Declaración de Río de 1992 (el Principio 2) y en múltiples tratados multilaterales medioambientales, que dan cuenta de la propia existencia del derecho internacional ambiental.

Es posible que la Corte haya incluido esta perspectiva clásica de la prevención como la básica obligación que tienen los Estados frente al derecho internacional, nos recuerda la propia naturaleza del medio ambiente, que tiene en las medidas preven-

22. Tener presente el contenido de nuestra nota al pie 4, respecto de los alcances de esta Opinión Consultiva que la misma Corte fija en el párrafo 243. 
tivas su fuerte. Un Estado que respeta los derechos humanos cumple con el principio de prevención en su sistema jurídico y se ocupa del cambio climático.

En materia climática, la mayoría de los Estados están en un proceso de construcción de un escenario para enfrentar el cambio climático que abarca un amplio espectro de medidas de mitigación y adaptación, algunas alojadas expresamente en el ámbito de políticas ambientales y otras muy relacionadas con políticas energéticas. Asimismo, la instrumentalización de esta obligación incluye la creación de institucionalidad que asuma el cambio climático en la agenda pública.

\section{Sobre el deber de aplicar el principio de precaución}

El cambio climático requiere un enfoque precautorio (Principio 15 de la Declaración de Río). La propia naturaleza del fenómeno nos indica que, si bien ya son apreciables los impactos, tener una idea acabada de qué significará para la humanidad el cambio climático es difícil de predecir, de allí la tarea continuada del IPCC, que se encuentra preparando su sexto reporte para el 2022. ${ }^{23}$

El principio precautorio requiere la inclusión expresa, dentro de los ordenamientos internos de los Estados, para asegurar la aplicabilidad no sólo en términos de cambio climático, sino en todo tema ambiental. Aquí se advierten tareas pendientes para muchos Estados americanos que no lo tienen incorporado en su derecho doméstico. ${ }^{24}$

En relación con los alcances, brevemente debe señalarse que este principio germinó para dar respuestas ante la incertidumbre generada por las actividades riesgosas junto con la sospecha de daño, para reducir los riesgos ambientales y a la salud, en un intento de servir de guía a las autoridades públicas en su proceso de toma de decisiones (Lucas Garín, 2010: 32).

En el marco de este principio, algo relevante es definir si se trata de un derecho o un deber que tendrá el Estado para tomar la medida precautoria, según Trouwborst (2006). Desde nuestra parte, pensamos que esto merece explorarse en contextos de cambio climático. ${ }^{25}$

La inclusión del principio precautorio en la Opinión Consultiva confirma el apoyo que está teniendo por la comunidad internacional, la que con amplitud —al decir

23. La COP 21 invitó al IPCC a proporcionar un informe especial en 2018 sobre las repercusiones del calentamiento global de $1,5{ }^{\circ} \mathrm{C}$ por encima de los niveles preindustriales y las rutas mundiales relacionadas con las emisiones de gases de efecto invernadero. El reporte fue publicado el 8 de octubre de 2018.

24. De manera importante, los autores apoyan que en materia ambiental el principio o enfoque precautorio es el adecuado. De todos modos, está claro que el mayor inconveniente pasa en materia de derecho positivo y la necesidad de avanzar en los derechos nacionales para su consagración. Esto sin considerar, por ejemplo, las sentencias de la Corte Internacional de Justicia, que aún no lo ha considerado en su jurisprudencia.

25. Para un análisis completo del principio precautorio, véase Trouwborst (2006: 386 y ss.). 
de Sands (2003: 272) — se está incorporando al tratamiento de variadas temáticas, dentro de las que se encuentra el cambio climático.

\section{Sobre la obligación de cooperar de buena fe para la protección del medio Ambiente}

Una manifestación de la obligaciones de cooperar en el régimen internacional de cambio climático se evidencia en las negociaciones climáticas, considerando las dificultades que estas negociaciones han tenido a la largo de casi 25 años, con un elevado número de partes y una temática basada en informaciones científicas - a cargo del IPCC - que se van renovando ante un nuevo y persistente problema, el cual es en extremo complejo y del que se derivan muchas implicancias sociales y económicas que aparecen en forma tácita en las negociaciones técnicas.

Esta obligación de cooperar de buena fe es un tema relevante en el derecho internacional ambiental, la cual es la gran herramienta de esta rama del derecho internacional, y que se renueva constantemente frente a las negociaciones de nuevos instrumentos multilaterales que exigen de los Estados americanos su participación. Ejemplo tenemos en las negociaciones concluidas del Acuerdo de Escazú. ${ }^{26}$

Pero las negociaciones no son sólo una manifestación de la cooperación de los Estados. El régimen internacional da cuenta de estas tendencias en cooperación internacional que podemos agrupar, siguiendo a Van Asselt, Mehling y Kehler Siebert (2016: 11-29) en: fragmentación institucional, los compromisos «blandos», la naturaleza cambiante de la diferenciación, el nacimiento de instrumentos de política innovadores, el incremento de la litigación climática y el traspaso del derecho internacional público a la gobernanza transnacional.

\section{Sobre el deber de notificar a otro Estado potencialmente afectado}

Este deber de notificar dentro del reciente Acuerdo de París puede interpretarse como una de las obligaciones que tienen las partes de presentar sus contribuciones determinadas a nivel nacional (NDC) cada cinco años respecto de sus emisiones de GEI, sus progresos y sus medidas para mitigarlo. ${ }^{27}$

El monitoreo del cumplimiento por los Estados de esta obligación será relevante para el periodo de implementación que se viene en el marco del Acuerdo de París, junto con otros mecanismos que pueden crearse en el régimen internacional.

26. Debe hacerse presente que, a la fecha, el Acuerdo de Escazú aún no entra en vigor, con un número importante de Estados que, si bien lo negociaron activamente, no lo han firmado, como es el caso de Chile.

27. Estas contribuciones deben ser un avance respecto de las obligaciones asumidas por esa parte hasta la fecha - un progreso- cada vez que la presentan. Es decir, deben incluir medidas más intensas y ambiciosas adoptadas en el marco de las obligaciones anteriores fijadas por ese Estado parte. 
Sobre el deber de garantizar el acceso a la información ambiental, la participación pública y el acceso a la justicia ambiental

Estos tres derechos se encuentran contemplados en el acuerdo regional que mencionamos recién en el ámbito americano, y que emula el Convenio de Aarhus en el ámbito europeo. ${ }^{28}$ Ellos generan deberes concretos para los Estados en la terminología elegida por la Opinión Consultiva.

Hoy los estándares internacionales para cumplir con estas obligaciones procedimentales del derecho humano al medio ambiente sano son más sofisticados, e indican que el Acuerdo de Escazú es al que deben adherir los Estados latinoamericanos. No en vano la Corte Interamericana lo menciona en esta Opinión.

\section{Conclusiones}

Luego de este breve recorrido por la Opinión Consultiva de la Corte, nos parece que ambos temas, tanto los derechos humanos como la lucha contra el cambio climático, comparten un requerimiento básico: la necesidad de implementación. Este tema, que imbrica en la relación del derecho internacional con el derecho nacional, se renueva frente a esta Opinión Consultiva, que podríamos caracterizar como un compendio del estado actual del derecho internacional ambiental con perspectiva de derechos humanos.

Si pensamos en un país como Chile, que está armando su propio escenario de cambio climático a partir de los compromisos internacionales renovados por el Acuerdo de París, podemos advertir posibles problemas en el diseño de las políticas climáticas, las que podrían aminorarse si de partida la dimensión de derechos humanos es atendida. Esto se suma a la posibilidad de que se restrinjan derechos Humanos o fundamentales — si queremos verlos desde el ámbito doméstico—; ${ }^{29}$ por ende, las

28. El Convenio sobre Acceso a la Información, Participación del Público en la Toma de Decisiones y Acceso a la Justicia en Materia de Medio Ambiente, conocido como Convenio de Aarhus, es un tratado internacional que regula los derechos de participación ciudadana en relación con el medio ambiente. El Convenio fue firmado el 25 de junio de 1998 en la ciudad danesa de Aarhus y entró en vigor el 31 de octubre de 2001.

29. La principal medida contra el cambio climático, la mitigación, pasa por limitar las emisiones de GEI. Esto devendrá en restricciones a los derechos, por ejemplo, de propiedad; por ello, hay una necesidad de cuidar la equidad climática de las cargas que se van imponiendo. En cuanto a las medidas de adaptación, si bien el objetivo es mejorar la resiliencia de la población frente al cambio climático, Fankhauser y McDermott (2016: 8) se refieren a las medidas de «adaptación transformacional», que son aquéllas que cumplen tres condiciones: son medidas de gran escala, contienen abordajes nuevos y el uso de instrumentos nuevos, e implican un cambio estructural de las actividades económicas o en su ubicación. En su aplicación puede haber restricciones a los derechos, aun cuando a largo plazo pueden ser beneficiosas para la población. 
posibilidades de conflictos que las medidas de mitigación y adaptación vayan generando exigen atender los derechos humanos en cada paso que se de en el ámbito doméstico. ${ }^{30}$

Si pensamos en derechos humanos, el cambio climático tiene el amargo efecto de demostrar que todos los derechos humanos son indivisibles, interdependientes y están interrelacionados (Sanz Caballero, 2013: 192). La Opinión Consultiva acrecienta el énfasis en la responsabilidad ambiental de los Estados dentro del derecho internacional de los derechos humanos (Grant, 2018: 114).

En nuestra opinión, la Opinión Consultiva habilita para la litigación climática en el marco del Sistema Interamericano, algo que los autores han pronosticado se incrementará en el futuro en cuanto a reclamaciones de casos de derechos humanos (Bähr y otros, 2018: 195), ante el fracaso de los Gobiernos en emprender acciones suficientes para enfrentar el fenómeno climático.

Esperamos que las enseñanzas de esta Opinión vayan siendo incorporadas por los Estados de nuestro continente, en especial frente al enorme desafío y la complejidad para las políticas públicas que requiere el cambio climático como problema retorcido o wicked problem.

\section{Reconocimiento}

Esta ponencia fue presentada en la Primera Bienal Latinoamericana de Estudios sobre Derecho Internacional de los Derechos Humanos de 2018, organizada por el Centro de Derechos Humanos de la Facultad de Derecho de la Universidad de Chile.

\section{Referencias}

Aguilar, Gonzalo (2017). «Los derechos ambientales en el Sistema Interamericano de Protección de los Derechos Humanos». En Henry Jiménez Guanipa y Javier Tous Chimá (coordinadores), Cambio climático, energía y derechos humanos: Desafíos y perspectivas (pp. 147-176). Barranquilla: Editorial Universidad del Norte y Fundación Heinrich Böll. Disponible en https://bit.ly/3mnyta4.

BäHr, Cordelia Christiane, Ursula Brunner, Kristin Casper y Sandra Lustig (2018). «Klima Seniorinnen lessons from the Swiss senior women's case for future climate litigation». Journal of Human Rights and the Environment, 9 (2): 194-221. DOI: 10.4337/jhre.2018.02.04.

30. Considérese que en Chile tiene trámite parlamentario el proyecto de ley marco de cambio climático desde enero del 2020. 
Bodansky, Daniel (2016). «The Paris Climate Change Agreement: A new hope?». The American Journal of International Law, 110 (2): 288-319. DOI: 10.5305/ amerjintelaw.110.2.0288.

BoyLe, Alan (2011). «Human rights and international environmental law: Some current problems». Disponible en https://bit.ly/37pfBTR.

BRAÑES, Raúl (2001). Informe sobre el desarrollo del derecho ambiental latinoamericano. Ciudad de México: Programa de las Naciones Unidas para el Medio Ambiente y el Desarrollo. Disponible en https://bit.ly/2WBnTSr.

Cepal, Comisión Económica para América Latina y el Caribe, y ACNUDH, Oficina del Alto Comisionado de las Naciones Unidas para los Derechos Humanos (2016). Sociedad, derechos y medio ambiente: Estándares internacionales de derechos humanos aplicables al acceso a la información, a la participación pública y al acceso a la justicia. Santiago: Naciones Unidas.

Fankahauser, Sam y Thomas McDermott (2016). «Climate-resilent development: An introduction». En Sam Fankahauser y Thomas McDermott (editores), The economics of climate-resilient development (pp. 1-11). Londres: Edward Elgar.

Ferrer MAC-Gregor, Eduardo (2017). La justiciabilidad de los derechos económicos, sociales, culturales y ambientales en el sistema interamericano de derechos humanos. Ciudad de México: CNDH, UNAM, Instituto de Investigaciones Jurídicas.

Godínez, Rodolfo y Thalía Viveros (2016). Cambio climático y derechos humanos. Ciudad de México: CNDH.

Grant, Evadne (2018). «Editorial indigeneity, human rights and the environment». Journal of Human Rights and the Environment, 9 (2): 113-118. DOI: 10.4337/ jhre.2018.02.00.

KnOx, John (2016). «Human rights principles and climate change». En Kevin R. Gray, Richard Tarasofsky y Cinnamon Carlarne (editores), The Oxford handbook of international climate change law (pp. 213-235). Oxford: Oxford University Press. DOI: 10.1093/law/9780199684601.003.0011.

LuCAS Garín, Andrea (2010). «Nociones del principio precautorio en el contexto internacional y su aplicación». Sociedad Chilena de Derecho Internacional: 27-35.

-. (2017). «Novedades del sistema de protección internacional de cambio climático: El Acuerdo de París». Estudios Internacionales, 1 (87): 137-167. DOI: 10.5354/0719-3769.2017.45222.

-. (2018). «Más de una década de cambio climático en Chile: Análisis de las políticas domésticas». Boletín Mexicano de Derecho Comparado, 51 (153): 587-625. DOI: 10.22201/iij.24484873e.2018.153.13651.

Peel, Jacqueline y Hari M. Osofsky (2015). Climate change litigation: Regulatory pathways to cleaner energy. Cambridge: Cambridge University Press.

Rittel, Horst y Melvin Webber (1973). «Dilemmas in a general theory of planning». Policy Sciences, 4 (2): 155-169. DOI: 10.1007/BF01405730. 
Sanz Caballero, Susana (2013). «Los efectos del calentamiento global en los derechos del niño: Una perspectiva desde el derecho internacional». Revista Española de Derecho Internacional, 65 (2): 191-207. Disponible en https://bit.ly/3oVTSZy.

SANDS, Philippe (2003). Principles of international environmental law. Cambridge: Cambridge University Press.

SCHÖNSTEINER, Judith (2018). «Proteger el medio ambiente más allá de las fronteras: Opinión Consultiva de la Corte IDH sobre medio ambiente y derechos humanos». Justicia Ambiental, 10 (10): 233-249. Disponible en https://bit.ly/30W8Miq.

Trouwborst, Arie (2006). Precautionary rights and duties of States. Leiden, Boston: Martinus Nijhoff.

VAn Asselt, Harro, Michael Mehling y Clarisse Kehler Sievert (2016). «The changing architecture of international climate change law». En Geert van Caster, Wim Vandenberghe y Leonie Reins (editores), Research handbook on climate change mitigation law (pp. 1-30). Londres: Edward Elgar.

VIÑUALes, Jorge (2017). «The Paris Agreement on Climate Change: Less is more». German Yearbook of International Law, 59: 12-44. DOI: 10.3790/978-3-428-55357-0.

\section{Sobre las autoras}

Andrea Lucas Garín es doctora en Derecho y Ciencias Sociales de la Universidad Nacional de Córdoba, Argentina. Master of Laws en Derecho Internacional de la Universidad de Heidelberg y de la Universidad de Chile. Directora del Instituto de Investigación en Derecho de la Universidad Autónoma de Chile. Su correo electrónico es andrea.lucas@uautonoma.cl. (D) https://orcid.org/0000-0003-4371-7418.

Tiare García Garcés es egresada de Derecho y asistente de investigación de la Facultad de Derecho de la Universidad Finis Terrae, Chile. Su correo electrónico es tfranciscao9@gmail.com. (D) https://orcid.org/oooo-0003-3929-7609. 
El Anuario de Derechos Humanos es una publicación semestral de referencia y consulta en materia de derechos humanos y campos afines. Busca ser un espacio de discusión de los temas centrales en el ámbito nacional e internacional sobre derechos humanos. Es publicado desde 2005 por el Centro de Derechos Humanos de la Facultad de Derecho de la Universidad de Chile.

\author{
EDITORA \\ Claudia Iriarte Rivas \\ ciriarter@derecho.uchile.cl \\ SITIO WEB \\ anuariocdh.uchile.cl \\ CORREO ELECTRÓNICO \\ anuario-cdh@derecho.uchile.cl \\ LICENCIA DE ESTE ARTÍCULO \\ Creative Commons Atribución Compartir Igual 4.o Internacional
}

\author{
\% \\ La edición de textos, el diseño editorial \\ y la conversión a formatos electrónicos de este artículo \\ estuvieron a cargo de Tipográfica \\ (www.tipografica.io)
}

